conjunction with the University Grants Committee of what has been achieved, and to examine in detail the question of possible extravagance. What must be avoided, however, is the sort of financial accountability which will endanger the originality and creative thought that the universities must safeguard at all costs and which would be a costly forfeit for saving a million or two of the taxpayers' money.

The income of the universities of Great Britain for the academic year $1948-49$ amounted to $£ 18,156,578$, of which $6 \cdot 7$ per cent was represented by endowments, 1.9 per cent by donations and subscriptions, 5 per cent by grants from local authorities, $59 \cdot 2$ per cent by Parliamentary grants, and $20 \cdot 6$ per cent by fees. The total income for English universities was $£ 14,588,360$, of which $£ 5,337,745$ was for London, $£ 1,664,926$ for Cambridge, $£ 1,332,674$ for Oxford and $£ 6,253,015$ for provincial universities and colleges. The total income for Wales was $£ 871,441$ and for Scotland $£ 2,696,777$. Compared with the previous year, total income rose by $£ 1,880,292$, chiefly by increases of $£ 1,338,923$ in Parliamentary grants and $£ 262,230$ in fees, which now represent $59 \cdot 2$ per cent and $20 \cdot 6$ per cent, respectively, of the total income. Income from endowments increased by $£ 18,166$.

Of the total expenditure of $£ 18,022,094$, the sum of $£ 323,305$ represented allocations to reserve, and the remainder was distributed as follows: administration, $9 \cdot 2$ per cent; departmental maintenance, $66 \cdot 3$ per cent; maintenance of premises, $11 \cdot 7$ per cent ; capital expenditure met from income, $2 \cdot 2$ per cent ; other maintenance expenditure, 10.6 per cent, the largest item under the last head being again the cost of the ordinary university examinations. Library expenditure totalled $£ 533,086$ for England, $£ 23,351$ for Wales and $£ 76,818$ for Scotland, approximately 3.6 per cent of the total expenditure, an increase of $£ 82,379$ on the previous year. No university deviated appreciably from this percentage; although in some of the London institutions the percentage reached more than 30, the average for all London institutions was 3.4. Figures for the three technical institutions shown were much lower, although that of 0.6 per cent for the Imperial College of Science and Technology appears to be attributed to ready access to the Science Library at the Science Museum. Of the total expenditure on libraries, $£ 340,298$ is on account of salaries and wages, $£ 162,091$ on account of books and $£ 64,774$ for periodicals. Only seven universities, Oxford (£28,328), Cambridge (£10,425), Birmingham $(£ 7,648)$, London $(£ 6,674)$, Edinburgh $(£ 6,524)$, Manchester $(£ 6,257)$ and Leeds $(£ 6,139)$ spent more than $£ 5,000$ on the purchase of books.

The full-time teaching staff increased from 6,536 to 7,390, and although the number of full-time students increased by 5,103 to 83,690 , there is thus a welcome increase in the ratio of staff to students. The increase in staff was made up of 85 professors, 563 lecturers, and 17 assistant lecturers and demon. strators, with a decrease of 7 in the number of readers, assistant professors and independent lecturers. Of the students, while there were 5,237 more men, there were 54 fewer women; although there was an increase of 204 women in Scotland. These were distributed as follows : arts, 44.4 per cent; pure science, $19 \cdot 2$ per cent; medicine, 16.8 per cent; technology, 13 per cent; agriculture, $3 \cdot 5$ per cent ; dentistry, $3 \cdot 1$ per cent. Of these 83,690 full-time students, 6,452 were engaged in research and other advanced work, 68,307 were reading for a first degree and 8,931 for a diploma; 61,554 were in England, 5,149 in Wales and 16,987 in Scotland, the English total comprising 15,082 at Oxford and Cambridge, 16,884 at London and 29,588 at provincial universities and colleges. Only at the University of Oxford was there a slight decrease in the number of full-time students. The proportion of full-time students residing in colleges and hostels was 22.7 per cent $(18.9$ per cent for men, 35.6 per cent for women), while $38 \cdot 2$ per cent were in lodgings and $39 \cdot 1$ per cent at home. Of overseas students from within the British Commonwealth, 3,335 were fulltime and 1,492 part-time; a further 2,589 full-time and 1,162 part-time students came from foreign countries. Cambridge again took 669 and Oxford 693 of these full-time students, Edinburgh 498, the London School of Economics 413 and University College, London, 375. A total of 24,826 full-time students was admitted for the first time during the year, an increase of 1,319 on 1947-48. There was little change in the general outlines of the distribution during the year; but there were 2,006 more men and 76 fewer women in arts, 575 more men and 159 more women in medicine and dentistry, 1,609 more men but 54 fewer women in pure science, 763 more men and 25 fewer women in technology and 284 more men but 58 fewer women in agriculture. Of the full-time students, $73 \cdot 7$ per cent were receiving assistance from Government departments, local authorities, universities or other bodies during the year, the percentage for England as a whole being 76, for Wales 81.8 and for Scotland $62 \cdot 9$. For the provincial universities, the figure $(78 \cdot 8)$ was slightly less than for either Cambridge $(79 \cdot 8)$ or Oxford $(81 \cdot 7)$, but higher than in the University of London $(66 \cdot 7)$.

Of the 18,180 part-time students, 4,335 were engaged in research or other advanced work, 2,171 were reading for a first degree and 2,826 for a diploma. Of such students engaged in advanced work 45.8 per cent were in medicine (including dentistry), 30.7 per cent in pure science and mathematics, $12 \cdot 6$ per cent in technology and 0.7 per cent in agriculture, a distribution contrasting markedly with that for fulltime advanced students of $37 \cdot 6$ per cent in pure science and mathematics, $9 \cdot 1$ per cent in medicine (including dentistry), and $3 \cdot 1$ per cent in agriculture, although the figure for technology $(13 \cdot 3$ per cent) is similar

\section{SCIENTIFIC CO-ORDINATION IN THE SOUTH PACIFIC}

$T$ HE welfare of the island peoples' in the South Pacific has become the objective of a six-nation co-ordinated undertaking known as the South Pacific Commission. Recognizing the mutual nature of many of the problems in the areas they administer, Australia, France, the Netherlands, New Zealand, the United Kingdom and the United States have joined in organizing the Commission to ". . . encourage and strengthen international co-operation in promoting the economic and social welfare and advancement of the peoples of the non-self-governing territories of the South Pacific region...." (Science, 3; May 26, 1950).

A research council has been established as an integral part of the Commission. Four specialists have been engaged to devote their full time to the undertaking, and other specialists will be retained to implement specific needs.

Projects to further the aims of the Commission are proposed after research by the council experts. They 
not only investigate the requirements of the area but also call on administrators and others who know the needs in the various territories to make recommendations; one of these suggestions led to the Seventh Pacific Science Congress which was held in New Zealand early in 1949. Council members are also guided by recommendations outlined by the commissioners representing member Governments. Proposals made for projects are submitted for final approval to the commissioners, who assemble for sessions twice a year. The four full-time members of the research council are assisted by a body of associate members; the full council meets annually to consider problems and needs of the South Pacific and to pass on projects to be submitted to the commissioners.

At the May 1949 session of the commissioners twenty-eight research projects in health, economic and social matters submitted by the research council were approved for action. Some of the projects are of an immediate nature; others will be developed on a long-term basis.

Financial support for the Commission comes from the member Governments, contributions to the annual budget being made as follows: Australia, 30 per cent ; France, $12 \frac{1}{2}$ per cent; the Netherlands, 15 per cent; New Zealand, 15 per cent; the United

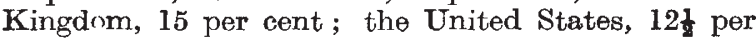
cent. The budget for 1950 was slightly in excess of $£ 144,000$ sterling.

Technical assistance to the various territories in its area is of vital concern to the Commission. Although the organization is entirely separate from the United Nations, liaison is maintained with that body and such of its affiliated and subsidiary bodies as will have common concern in the South Pacific. This is particularly true in regard to the World Health Organization, the Food and Agriculture Organization, and the Indo-Pacific Fisheries Council. The South Pacific Commission is modelled on its successful prototype in the western hemisphere, the Caribbean Commission, several of the same member Governments being concerned.

\section{ONTARIO RESEARCH FOUNDATION \\ ANNUAL REPORT FOR 1949}

$\mathrm{T}$ HE annual report for 1949 of the director of research of the Ontario Research Foundation* characterizes the year as one of transition to con. ditions which from an economic point of view are regarded as more normal. The fellowship work of the Foundation continued at a high level, though sometimes the absence of men and women with specialized postgraduate experience prevented the establishment of a new fellowship. The short-term work in the laboratories continued to grow, largely due to the work of the Department of Industrial Research Services, which was utilized by 1,910 different companies on 2,853 occasions, laboratory work being involved in about half of these. This assistance to the smaller industrialists is paid for by them on a reasonable basis of cost. A list of papers published during 1949 is appended, together with the balance sheet and statement of income and expenditure.

- Ontario Research Foundation. Annual Report for 1949. Pp. 24. (Toronto: Ontario Research Fonndation, 1950.)
In the Department of Biochemistry progress is reported in the investigation of the chemistry of flavone reversion in linseed and other vegetable oils, of the effect of oxidation on the infra-red spectra of hydrogenated and unhydrogenated oils, and the formation of trans isomers of fatty acids during the polymerization of linseed oil. An X-ray method for the non-destructive testing of footwear used by the Armed Services has been devised, involving the use of treated thread which is clearly visible in a fluorescent screen, the thread being also made resistant to moulds by the treatment. A new laboratory was organized to study problems associated with the making of tomato products.

Considerable attention has been given to the organization of the laboratories in the Department of Chemistry which are responsible for short-term work. Investigations of the repair of methyl methacrylate dentures under the dental materials research fellowship have been concluded and the results published, while work on the use of methyl methacrylate for direct intra-oral fillings has been concerned mainly with methods for providing the localized heating necessary for polymerization in situ. Detailed reports have been made on the essential oils from the foliage of black spruce and hemlock trees, and considerable progress has been made in the study of the chemistry of white birch.

The Department of Engineering and Metallurgy has maintained basic research fellowship projects and short-term investigations at a high level, but has been obliged to reduce to a minimum purely routine service such as specialized heat treatment. The latest type of Bausch and Lomb metalloscope has been added to the equipment for metallography, and the Department has been asked to investigate possible methods of reducing coke consumption in Canadian blast furnaces by the use of electric smelting equipment. An investigation initiated into the nondestructive testing of metals has led to the discovery that failure can be predicted long before it occurs by tracing the changes in the magnetic properties of steel parts.

In the Department of Parasitology the work on the protozoan blood parasites of birds has been almost entirely confined to the species occurring in wild ducks. The work on Ascaris lumbricoides has been directed towards isolating a substance which will protect against infection. Preliminary investigations have been made of the conditions responsible for 'swimmers' itch' or cercarid dermatitis, which has a wide but irregular distribution. The Department of Physiography has been concerned chiefly with details associated with the publication of the physiographical map of southern Ontario and the accompanying monograph.

In the field of textiles, the fellowship sponsored by Courtaulds (Canada), Ltd., has completed a thorough study of statistical methods for determining the sizes of women's garments and has investigated the density, swelling and regain of viscose rayon yarns. The York Knitting Mills fellowship has been concerned chiefly with designing and assembling the equipment for a fundamental study of principles involved in the commercial production of worsted yarn, and the Canadian Industries, Ltd., nylon fellowship has been devoted to a study of those properties of the nylon fibre which determine the commercial properties of the finished fabric. Some independent work has been commenced on the elastic properties of textile fibres, for which purpose nylon is being investigated first. 